\title{
The exocyst at the interface between cytoskeleton and membranes in eukaryotic cells
}

\author{
Lukáš Synek ${ }^{1}$, Juraj Sekereš ${ }^{1,2}$ and Viktor Žárský1,2 * \\ ${ }^{\prime}$ Laboratory of Cell Biology, Institute of Experimental Botany, Academy of Sciences of the Czech Republic, Prague, Czech Republic \\ 2 Laboratory of Plant Cell Biology, Department of Experimental Plant Biology, Faculty of Science, Charles University in Prague, Prague, Czech Republic
}

\section{Edited by:}

Christopher J. Staiger, Purdue

University, USA

Reviewed by:

Andreas Nebenführ, University of

Tennessee, USA

Frantisek Baluska, University of Bonn,

Germany

\section{*Correspondence:}

Viktor Žárský, Laboratory of Plant Cell Biology, Department of Experimental Plant Biology, Faculty of Science, Charles University in Prague, Vinicna 5, 12844 Prague, Czech Republic e-mail: zarsky@ueb.cas.cz
Delivery and final fusion of the secretory vesicles with the relevant target membrane are hierarchically organized and reciprocally interconnected multi-step processes involving not only specific protein-protein interactions, but also specific protein-phospholipid interactions. The exocyst was discovered as a tethering complex mediating initial encounter of arriving exocytic vesicles with the plasma membrane. The exocyst complex is regulated by Rab and Rho small GTPases, resulting in docking of exocytic vesicles to the plasma membrane (PM) and finally their fusion mediated by specific SNARE complexes. In model Opisthokont cells, the exocyst was shown to directly interact with both microtubule and microfilament cytoskeleton and related motor proteins as well as with the PM via phosphatidylinositol 4,5-bisphosphate specific binding, which directly affects cortical cytoskeleton and PM dynamics. Here we summarize the current knowledge on exocystcytoskeleton-PM interactions in order to open a perspective for future research in this area in plant cells.

Keywords: exocyst, actin cytoskeleton, microtubule cytoskeleton, phospholipids, myosin, small GTPases, Exo70, secretion

\section{THE EXOCYST AS A REGULATORY HUB IN THE ACTIVE CELL CORTEX}

Polarized surface growth in eukaryotic cells involves interactions between the cytoskeleton and membrane transport pathways. The last steps of the secretory pathway taking place in the vicinity of the plasma membrane (PM) are regulated by an array of small GTPases, the exocyst tethering complex, and SNARE proteins. The exocyst is a protein complex comprising eight subunits (Sec3, Sec5, Sec6, Sec8, Sec10, Sec15, Exo70, and Exo84) engaged in docking and tethering of secretory vesicles, providing a spatial and temporal regulation of exocytosis (Hsu et al., 1996; TerBush et al., 1996) and interacting directly or indirectly with membranes, cytoskeletal proteins, as well as with small GTPases from the Rab, Ral, and Rho subfamilies and many other proteins in the cell cortex (Wu et al., 2008). As such, the exocyst seems to act as an integrating hub in the cell cortex, mainly in the context of exocytosis. In general, proper exocyst function is essential for polar growth and cell morphogenesis, including invadopodia, lamellipodia, and neuronal dendrites formation in animal cells, bud growth in budding yeast, and cytokinesis in fission yeast (reviewed in Heider and Munson, 2012; Vaškovičová et al., 2013; Figure 1). A growing number of papers document functions of the plant exocyst in similar processes with high demand for exocytosis, including root hair growth, hypocotyl cell elongation, cytokinesis, seed coat formation and papilla formation after a pathogen attack in plants (Synek et al., 2006; Hála et al., 2008; Fendrych et al., 2010; Kulich et al., 2010; Pecenkova et al., 2011; Vaškovičová et al., 2013).

\section{THE EXOCYST AND ACTIN CYTOSKELETON}

Deep insight into exocyst functions and their mechanisms came from genetic studies on budding yeast, where the exocyst was originally discovered as a protein complex (Novick et al., 1980; TerBush etal., 1996). In budding yeast cells, secretory vesicles are transported along formin- and Arp2/3-generated actin cables. A common model of the exocyst action suggests that most exocyst subunits arrive to the PM in association with secretory vesicles and cannot localize properly after disruption of the actin cytoskeleton (Boyd et al., 2004; Bendezú et al., 2012). However, Sec3p and part of the Exo70p population can reach its destination, a newly forming bud, independently of the actin cytoskeleton probably via direct association with Rho GTPases (Boyd et al., 2004). Therefore, Sec3p and Exo70p are supposed to act as landmarks of sites for the exocyst localization and action (Finger etal., 1998; Boyd et al., 2004).

Mutations in several exocytosis-related genes cause actin cytoskeleton defects in budding yeast, leading subsequently to impaired cell growth and morphogenesis and also to an mRNA transport and polarization defect that is actin-dependent (Aronov and Gerst, 2004). The identified genes included those encoding SEC10 and SEC15 exocyst components and CDC42 and $\mathrm{RHO} 3$ GTPases regulating the exocyst polar targeting (Wu et al., 2008).

An interesting reciprocal relationship was observed during cell wounding response, where Sec3p and the Bnilp formin are degraded in order to eliminate competition for secretory vesicles required to repair the damaged membrane and cell wall, which are arriving along the pre-polarized cytoskeleton directing current polarized growth. The Bnrlp formin and the Exo70p exocyst subunit relocalize to the damage site followed by redistribution of the Myo2p myosin and delivery of new material (Kono et al., 2012). 


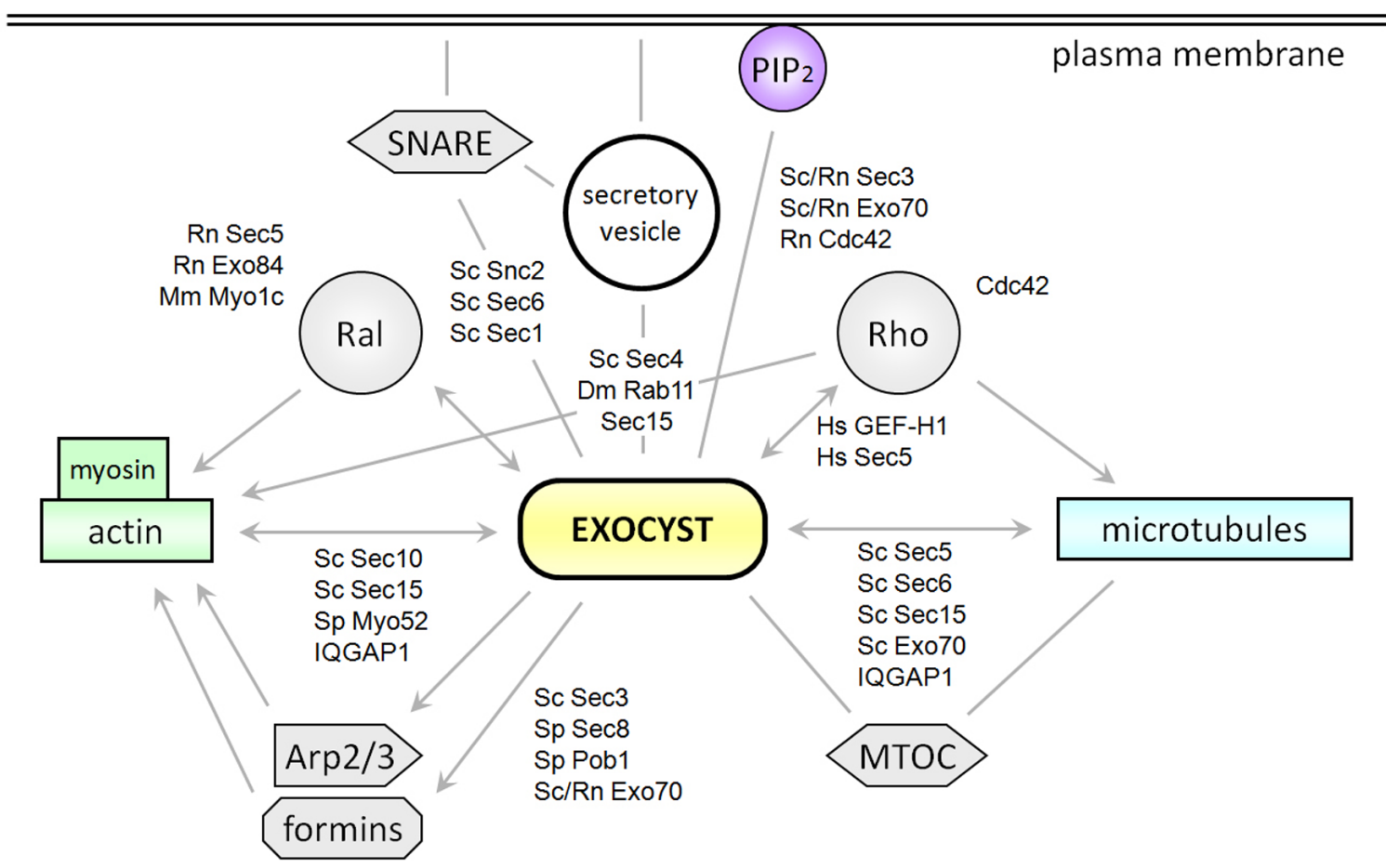

FIGURE 1 | Interactions of the exocyst complex with the cytoskeleton, plasma membrane, and associated proteins. Scheme of exocyst interactions described in the text, including the key players Ral and Rho GTPases, SNARE proteins, formins, and the Arp2/3 actin-nucleating complex, microtule-organizing center (MTOC) and phosphatidylinositol 4,5-bisphosphate $\left(\mathrm{PIP}_{2}\right)$ at the plasma membrane. Dm, Drosophila melanogaster; Mm, Mus musculus; Hs, Homo sapiens Rn, Ratus norwegicus; Sc, Saccharomyces cerevisiae; Sp, Schizosaccharomyces pombe.
In budding yeast, cell polarity and polarized exocytosis is coordinated also by the Rho3p GTPase (Adamo et al., 1999), which can regulate both actin polarity and transport of exocytic vesicles from mother cell to the bud, as well as vesicle docking to the PM. While the Rho3p vesicle delivery function is mediated by Myo2p, the docking requires Exo70p (Adamo et al., 1999).

In the fission yeast Schizosaccharomyces pombe, the actin cytoskeleton is dispensable for proper exocyst localization and polarized growth (Bendezú and Martin, 2011; Snaith et al., 2011). While actin-independent polar transport in budding yeasts might be constrained by the narrow bud neck, and bud growth requires motor-driven transport along actin cables, the open cylindrical shape of fission yeast cells may allow actin-independent vesicle transport (Bendezú and Martin, 2011). However, the exocyst and actin cytoskeleton share at least two common upstream regulators - Cdc42 (Estravís et al., 2011) and Pob1 (Nakano et al., 2011).

The polar exocyst localization and formation of actin cables are dependent on and mutually coupled by Pob1 via its interaction with the For3 formin and the Sec8 exocyst subunit, respectively. Simultaneous deletion of For 3 and Sec 8 results in isotropic growth, indicating a functional redundancy between microfilaments and the exocyst in cell polarization (Bendezú and Martin, 2011). In contrast, although unable to divide properly, sec8 exo70 and sec6 $\sec 8$ double mutants are still capable of polarized growth (Bendezú and Martin, 2011).

Although all fission yeast exocyst subunits can localize to cell poles largely independently of the actin cytoskeleton, at least Sec3,
Sec5, and Exo70 (most probably as a part of the complete exocyst complex) are more efficiently transported to the cell apex by the Myo52 myosin V along microfilaments (Snaith et al., 2011; Bendezú et al., 2012). Either functional Sec3 or Exo70 is essential for viability and proper localization of other exocyst subunits, suggesting that, as in budding yeast, these two components act as exocyst tethers at the PM (Bendezú et al., 2012). A polarization pathway involving the exocyst relocalization and actin repolarization downstream of Cdc42 also participates in fission yeast mating (Bendezú and Martin, 2013).

Unexpectedly, the fission yeast Sec3 not only acts in exocytosis but also marks sites for actin recruitment and controls overall actin organization via direct binding of For3 (Jourdain et al., 2012). Mutants in Sec3 exhibit lack of microfilaments, depolarized actin patches, and disassembly of the cytokinetic actomyosin ring probably due to a failure in polarization of the For3 formin.

The Exo70 exocyst subunit also interacts both in vitro and in vivo with the yeast and rat Arpc1/Arc40 subunit of the Arp2/3 complex, a key regulator of actin polymerization. Inhibition of the Exo70 function in rat kidney cells blocks formation of actin-based membrane protrusions and affects cell migration (Zuo et al., 2006), pointing to yet unknown capacity of Exo70 to regulate the actin organization and coordinating thus actin cytoskeleton with membrane trafficking during cell migration. Exo70 was recently shown to promote Arp2/3-driven microfilament nucleation and branching (Liu et al., 2012). Because both the 
exocyst and Arp2/3 complexes are well conserved across eukaryotes, including plants, their interaction is likely to be conserved as well.

In mammalian cells, actin organization, as well as membrane trafficking, cell growth and differentiation, is regulated by RalA and RalB, ubiquitous small GTPases from the Ras superfamily (Feig etal., 1996). Activated (GTP-bound) RalA forms a stable complex with the exocyst via binding to Sec5 (Brymora et al., 2001; Sugihara et al., 2002; Fukai et al., 2003) and Exo84 (Moskalenko et al., 2003; Jin et al., 2005) exocyst subunits in human and rat cells. Specific inhibition of the Sec5 activity blocks filopodia formation in $3 \mathrm{~T} 3$ cells, a dynamic process that is highly dependent on actin reorganization and that can be normally induced by RalA or cytokines via Cdc42 (Sugihara et al., 2002). This inhibitory effect could not be attributed to disrupted secretion, since inhibition of secretion by brefeldin A did not affect filopodia formation (Sugihara et al., 2002), indicating that the exocyst-RalA complex may regulate actin reorganization independently of vesicle transport. Both RalA-Sec5 and RalA-Exo84 interactions are necessary for proper regulation of the actin cytoskeleton dynamics, as documented by different morphological consequences of uncoupling these interactions in PC-3 cells, such as defects in lamellipodia formation, rounder cells or extended spindles (Hazelett and Yeaman, 2012). RalA also interacts with the actin cytoskeleton via Myolc, suggesting its function as a cargo receptor for the Myolc motor (Chen et al., 2007). Taken together, the exocyst complex as an immediate effector of RalA obviously integrates the secretory pathway and actin cytoskeleton near the PM in mammalian cells (Figure 1).

Cells of mouse oocytes can use secretory (Rab11-positive) vesicles associated with the exocyst components via the Rab11-Sec15 interaction (Wu etal., 2005) as adaptable, motorized network nodes regulating the dynamics and density of microfilaments in a myosin Vb-dependent manner (Holubcová et al., 2013). Such an actin modulation is essential for asymmetric positioning of the meiotic spindle and thus for the development of a fertilizable egg in mammals.

Although we can find no dynamic membrane protrusions analogous to filopodia in plant cells, fine F-actin meshwork is essential for polar growth of root hairs, pollen tubes, or stigmatic papillae and this type of growth demanding precise regulation of exocytosis is also strongly dependent on the exocyst function (Yalovsky et al., 2008; Vaškovičová et al., 2013).

Ral GTPases are specific to animals - in plant cells, as in yeast, only homologs to Rho GTPases (called also Rac in animals) are present and due to some plant specific features they are called Rop (Rho of plant). Rop GTPases were clearly implied in the cortical cytoskeleton regulation mostly possibly via plant specific Rop-interacting adaptors (RICs; Fu et al., 2001; Yalovsky et al., 2008). Very significant for the speculations on plant exocystcytoskeleton links is a dominant land-plant specific way of Rop activation mediated by specific PRONE-GEF (plant-specific ROP nucleotide exchanger - GDP/GTP exchange factor) regulated by interacting receptor-like kinases (RLKs) that allow for very efficient cortical activation of Rop GTPases in response to plethora of different stimuli including changes in cell wall mechanics (Mucha et al., 2011). Moreover, the first Rop-exocyst interaction observed in plants is not direct - several GTP-bound Rops interact with the Sec3 exocyst subunit in Arabidopsis via a plant specific adaptor protein ICR1 which is implied in the regulation of auxin polar transport (Lavy et al., 2007; Hazak et al., 2010; see further). These features along with plant specific transmembrane anchorage of plant F-actin nucleating formins (Cvrčková, 2013; in this issue) indicate that the cortical wiring between actin cytoskeleton and exocytosis in plants will be quite specific.

\section{THE EXOCYST AND TUBULIN CYTOSKELETON}

Microtubules are not essential for exocytosis in budding yeast and no functional link with the exocyst complex has been documented so far (Hammer and Sellers, 2012). In rat kidney cells, however, Exo70 co-localizes with microtubules and the mitotic spindle, and in vitro, the exocyst complex reconstituted from recombinant subunits inhibits tubulin polymerization. However, deletions of any of Sec5, Sec6, Sec15, or Exo70 exocyst subunits diminished the inhibition activity. Surprisingly, Exo70 itself could inhibit tubulin polymerization, albeit the exocyst complex lacking the Exo70 subunit did not lose its activity completely. On the other hand, when Exo70 was overexpressed, the microtubule network became disrupted and filopodia-like PM protrusions were formed (Wang et al., 2004).

The protrusion formation is consistent with an observation in Xenopus neurons, where a local disassembly of microtubules by focal application of nocodazole induced an addition of a new membrane material at the affected site (Zakharenko and Popov, 1998).

In undifferentiated PC12 neuronal cells, the exocyst complex is associated with microtubules as well as microtubule organizing centers and can be co-immunoprecipitated with microtubules from the total rat brain lysate (Vega and Hsu, 2001). However, upon activation of neuronal differentiation, the exocyst redistributes from perinuclear localization to the growing neurite characterized by high exocytic activity at the PM. The subcellular exocyst localization was affected by treatment with microtubuledisrupting drugs, but not actin-disrupting drugs. These results support a possibility that the exocyst complex acts as a modulator of microtubules to mediate vesicle targeting in animal cells.

It is expected that also in respect to microtubular cytoskeletonsecretory pathway relationship the plant cells will have specific features due to the obvious dependence of the final steps of exocytosis and membrane recycling in plants on the actin cytoskeleton and very possibly exocytosis permissive feature of even dense cortical microtubuli (see below). However, both cytoskeletal systems in plant cells strongly interact (e.g., via specific actin nucleating formins) so that in the real biological context it will be challenging to separate their functions.

\section{INTERPLAY BETWEEN THE EXOCYST AND BOTH TYPES OF CYTOSKELETON}

In contrast to budding yeast, typical vertebral cells use microtubules for long-range cargo transport and microfilaments for short-range transport in cell cortex during later steps of vesicles traffic (Hammer and Sellers, 2012). Several studies pinpoint the potential importance of the exocyst in transition of cargo from microtubules to microfilaments. 
Mammalian cell migration involves cooperative reorganization of the actin and microtubule cytoskeletons under the control of Rho GTPases (de Curtis and Meldolesi, 2012). Proper localization and activity of the exocyst is promoted by microtubuleassociated GEF-H1, a GTP exchange factor for the RhoA actin activator, in HeLa cells (Pathak et al., 2012). Microtubule depolymerization results in the activation of GEF-H1, which further activates RhoA (Krendel et al., 2002). Importance of this regulation was documented experimentally on the cleavage furrow formation during cytokinesis (Birkenfeld etal., 2007) and on actin dynamics during cell migration (Nalbant et al., 2009). The depletion of GEF-H1 led to accumulation of Rab11-positive secretory vesicles within the cells and to mislocalization of Exo70 and Sec8 exocyst subunits (Pathak et al., 2012). GEF-H1 also directly binds the Sec5 exocyst subunit in a RalA GTPasedependent manner; the interaction is stronger with free GEFH1 than with its microtubule associated form (Pathak et al., 2012). The Sec5-GEF-H1 interaction promotes RhoA activation, which then regulates exocyst localization and possibly its assembly, as well as actin polymerization. Exocyst thus first helps to activate RhoA, which subsequently assists functioning of the exocyst, resulting in a positive feedback (Pathak et al., 2012).

Interestingly, despite the different mechanisms of cytokinesis between plants and animals/fission yeast (contraction versus building of a cell plate), the exocyst is involved in both types of cytokinesis (Fendrych et al., 2010).

IQGAP1 is another important regulator of both actin and microtubular cytoskeleton associated with the exocyst. The active RhoA and Cdc42 trigger association of Sec3 and Sec8 exocyst subunits with IQGAP1. This interaction is essential for MT1MMP protease localization at invadopodia and thus for proper invadopodia functioning (Sakurai-Yageta et al., 2008). IQGAP1 stimulates actin bundling (White et al., 2012) and directly interacts with microtubule plus end binding protein CLIP-170 in neurons (Swiech et al., 2011).

\section{EXOCYST INTERACTION WITH CELLULAR MEMBRANES}

As mentioned earlier, in budding yeast, Sec3p and part of Exo70p population can reach newly forming bud also independently of microfilaments (Boyd et al., 2004). They bind the PM directly via phospholipid phosphatidylinositol 4,5-bisphosphate $\left(\mathrm{PIP}_{2}\right)$ and indirectly by association with Rho GTPases (He et al., 2007; Zhang et al., 2008; Wu et al., 2010; Figure 1). Sec15p binds to the membrane of secretory vesicles via the Sec4p Rab GTPase (Guo et al., 1999) and Sec6p binds Snc2p, a vesicle-associated SNARE protein (Shen et al., 2013). Sec6p also contributes to anchor the exocyst complex at sites of secretion - possibly via interaction with PM-associated proteins (Songer and Munson, 2009). Besides facilitating exocytosis by interactions with Sec9p, a Qbc exocytic t-SNARE protein (Sivaram et al., 2005), and with Sec1, a protein from the Sec1/Munc18 family regulating SNARE functions (Morgera et al., 2012), the exocyst also interacts with the vesicles transporting myosin Myo2p (also a known Sec4p interactor) via the Sec15p subunit that directly binds the motor and allows for its release after vesicle tethering (Jin et al., 2011; Donovan and Bretscher, 2012).
In fission yeast, Sec6 and Sec8 exocyst subunits localize to cell tips largely independent of the actin cytoskeleton, but in a Cdc42 and $\mathrm{PIP}_{2}$-dependent manner. Thus, the fission yeast long-range cytoskeletal transport and $\mathrm{PIP}_{2}$-dependent exocyst represent parallel morphogenetic modules downstream of $\mathrm{Cdc} 42$, raising the possibility of similar mechanisms in other organisms (Bendezú and Martin, 2013). Bendezú et al. (2012) showed that Sec3 and Exo70 tether the exocyst complex arriving with secretory vesicles by direct binding to $\mathrm{PIP}_{2}$ and Rho GTPases at the cell poles. In absence of the Myo52 motor protein, vesicles with the entire exocyst can still reach the cell pole by random movement, but less efficiently. In absence of both Sec3 and Exo70, vesicles and the rest of the exocyst fail in delivery and tethering and form aggregates. Also in plants Sec3 subunit of exocyst interacts with membrane lipids (Bloch et al., in preparation).

Very recently Zhao et al. (2013) discovered that Exo70 alone, through an oligomerization-based manner, can generate membrane curvatures in vitro independent of the exocyst function. This represents a mechanism creating protrusions even in the absence of actin, albeit it is not clear to what extent stimulated actin polymerization, membrane delivery, and membrane deformation contribute to cell shape changes in vivo including formation of membrane protrusions. Thus, Exo70 as a membrane-bending protein may couple the actin dynamics and PM remodeling in morphogenesis.

The exocyst is also essential for large-particle phagocytosis (Mohammadi and Isberg, 2013), Salmonella invasion into host cells (Nichols and Casanova, 2010) and formation of tunneling nanotubes - recently discovered structures connecting cytoplasm of animal cells (Ohno et al., 2010; Mukerji et al., 2012; Schiller et al., 2013). Each of these events could combine all three mechanisms mentioned above. Membrane-deforming ability of Exo70 could function well beyond the cell cortex-associated events, since the exocyst participates in many cellular processes (reviewed in Heider and Munson, 2012; Liu and Guo, 2012).

\section{PERSPECTIVES ON THE EXOCYST-CYTOSKELETON INTERFACE IN ENDOMEMBRANE BIOGENESIS IN PLANTS}

Regulation of the cytoskeleton structure and dynamics in plant cells is very much affected by the cell wall, implying close proximity between secretory pathway, cell wall biogenesis and cortical cytoskeleton. These cellular systems are regulated by small GTPases, especially from the ARF, RAB, and ROP families, major regulators of the cell polarity and morphogenesis closely related to their fungal or animal counterparts (Vaškovičová et al., 2013). Work in the laboratory of Shaul Yalovsky (Lavy et al., 2007; Hazak et al., 2010) showed that the SEC3 exocyst subunit interacts with an activated (GTP-bound) ROP at the PM via ICR1, a founding member of the ICR/RIP protein family (Li et al., 2008; Mucha et al., 2010). RIP3 (also known as MIDD1) interacts in a GTP-bound manner with ROPs and also with the Kinesin-13A to regulate the microtubular dynamics (Mucha et al., 2010). RIP3 is a crucial negative regulator of cortical microtubules in the patterning of secondary cell wall thickening directed by the ROP11 GTPase module (Oda and Fukuda, 2012). At PM sites, where cortical microtubules are locally destabilized, the localized exocytosis-dependent secondary cell wall thickening is blocked (Oda and Fukuda, 2012). 
While local destabilization of cortical microtubules seems to stimulate exocytosis in animal cells (see above Zakharenko and Popov, 1998), dense microtubule cortical domains of somatic plant cells are often the cortical domains of highest secretory activity, as in xylem thickening or seed coat epidermal cells with a volcano-like cell wall thickening, where highly polarized delivery of pectins is targeted to extremely dense cortical microtubule domains (McFarlane et al., 2008; Oda and Fukuda, 2012). The exocytosis of pectins into pectin-accumulating pockets depends on exocyst function, implying a possibility that microtubule-rich domains might be a general cortical target recognized by EXO70s or other exocyst subunits, functioning as putative PM landmarks for exocytosis targeting (Žárský et al., 2009; Kulich et al., 2010). Extensive proliferation of the EXO70 gene in land plants (e.g., Arabidopsis in endowed with 23 EXO70 paralogs) possibly provides a potential for fine targeting into specific cortical areas (Synek et al., 2006; Cvrčková et al., 2012).

On the contrary, dense cortical microfilament meshwork might block exocytosis in both animal and plant cells (Valentijn et al., 1999; Žárský et al., 2009). For instance, a dense subapical F-actin fringe separating actively growing tip from the rest of the tobacco pollen tube might also be a mechanical obstacle for exocytosis (Lovy-Wheeler et al., 2005). The exocyst is also accumulated at the tip of growing pollen tubes and is obviously involved in exocytosis (Hála et al., 2008). The transport and delivery of secretory vesicles in plant cells is likely to depend on both microfilaments and an interaction of some exocyst subunits with the PM phosphoinositides, like in the case of yeast and animal cells (see above). Phosphoinositide binding was indeed predicted for several Arabidopsis EXO70 paralogs based on yeast and animal models (Žárský et al., 2009) and currently proved both biochemically and cytologically in our laboratory for the Arabidopsis SEC3 exocyst subunit (Bloch et al., in preparation).

The dynamics of several exocyst subunits at the PM, as monitored by TIRF microscopy in Arabidopsis epidermal cells, was unaffected by actin or microtubule cytoskeleton disruption after short $(10 \mathrm{~min})$ treatment with inhibitors, however, prolonged actin cytoskeleton disruption $(1 \mathrm{~h})$ resulted in exocyst redistribution and aggregation at the PM and impaired dynamics (Fendrych et al., 2013). This is consistent with microfilament involvement not only in the delivery but also in spatial distribution of secretory vesicles and endomembrane compartments (Staehelin and Moore, 1995).

Interestingly, exocyst complexes show almost no lateral movement within the PM in both plant and animal cells, as analyzed by the TIRF microscopy, and very similar time of persistence at the PM of about $10 \mathrm{~s}$ was recorded (Fendrych et al., 2013; Rivera-Molina and Toomre, 2013). Similarly, the KAT1 channel is localized inside the PM within positionally stable microdomains, which last, however, for 10 s of minutes, in contrast to dynamics of the exocyst (Sutter et al., 2006). It is possible that some transmembrane proteins, e.g., plant-specific transmembrane formins (Martiniere etal., 2011; Cvrčková, 2013; in this issue) create, together with specific membrane lipids, functional clusters stabilized against the lateral movement in the PM. These transmembrane proteins might be immobilized by the binding extracellular domains in the cell wall matrix and provide landmarks for the delivery of secretory vesicles (Martinière et al., 2012).

\section{CONCLUSION}

Direct as well as a circumstantial evidence accumulated over the years concerning interactions and cooperation between the exocyst and cytoskeleton indicates that the exocyst, cytoskeleton, and membrane traffic meet at the active cellular cortex. The exocyst serves an important role in co-ordination of the vesicle trafficking with the cytoskeleton in eukaryotes, in addition to its canonical role in exocytosis. In plant cells, however, we have currently only limited and indirect evidence for this regulatory interplay, urging further research in this direction.

\section{ACKNOWLEDGMENTS}

This work was supported by the Czech Science Foundation (GACR project GPP501/11/P853) and EU-ITN grant No. 238640PLANTORIGINS. The authors thank F. Cvrčková for critical reading of the manuscript.

\section{REFERENCES}

Adamo, J. E., Rossi, G., and Brennwald, P. (1999). The Rho GTPase Rho3 has a direct role in exocytosis that is distinct from its role in actin polarity. Mol. Biol. Cell 10, 4121-4133. doi: 10.1091/mbc.10.12.4121

Aronov, S., and Gerst, J. E. (2004). Involvement of the late secretory pathway in actin regulation and mRNA transport in yeast. J. Biol. Chem. 279, 36962-36971. doi: 10.1074/jbc.M402068200

Bendezú, F. O., and Martin, S. G. (2011). Actin cables and the exocyst form two independent morphogenesis pathways in the fission yeast. Mol. Biol. Cell 22, 44-53. doi: 10.1091/mbc.E10-08-0720

Bendezú, F. O., and Martin, S. G. (2013). Cdc42 explores the cell periphery for mate selection in fission yeast. Curr. Biol. 23, 42-47. doi: 10.1016/j.cub.2012.10.042

Bendezú, F. O., Vincenzetti, V., and Martin, S. G. (2012). Fission yeast Sec3 and Exo70 are transported on actin cables and localize the exocyst complex to cell poles. PLoS ONE 7:e40248. doi:10.1371/journal.pone.0040248

Birkenfeld, J., Nalbant, P., Bohl, B. P., Pertz, O., Hahn, K. M., and Bokoch, G. M. (2007). GEF-H1 modulates localized RhoA activation during cytokinesis under the control of mitotic kinases. Dev. Cell 12, 699-712. doi: 10.1016/j.devcel.2007.03.014

Boyd, C., Hughes, T., Pypaert, M., and Novick, P. (2004). Vesicles carry most exocyst subunits to exocytic sites marked by the remaining two subunits, Sec3p and Exo70p. J. Cell Biol. 167, 889-901. doi: 10.1083/jcb.200408124

Brymora, A., Valova, V. A., Larsen, M. R., Roufogalis, B. D., and Robinson, P. J. (2001). The brain exocyst complex interacts with RalA in a GFPdependent manner: identification of a novel mammalian Sec3 gene and a second Sec15 gene. J. Biol. Chem. 276, 29792-29797. doi: 10.1074/jbc.C10 0320200

Chen, X. W., Leto, D., Chiang, S. H., Wang, Q., and Saltiel, A. R. (2007). Activation of RalA is required for insulin-stimulated Glut4 trafficking to the plasma membrane via the exocyst and the motor protein Myolc. Dev. Cell 13, 391-404. doi: 10.1016/j.devcel.2007.07.007

Cvrčková, F. (2013). Formins and membranes: anchoring cortical actin to the cell wall and beyond. Front. Plant Sci. 4:436. doi: 10.3389/fpls.2013.00436

Cvrčková, F., Grunt, M., Bezvoda, R., Hála, M., Kulich, I., Rawat, A., et al. (2012). Evolution of the land plant exocyst complexes. Front. Plant Sci. 3:159. doi: 10.3389/fpls.2012.00159

de Curtis, I., and Meldolesi, J. (2012). Cell surface dynamics - how Rho GTPases orchestrate the interplay between the plasma membrane and the cortical cytoskeleton. J. Cell Sci. 125, 4435-4444. doi: 10.1242/jcs. 108266

Donovan, K. W., and Bretscher, A. (2012). Myosin-V is activated by binding secretory cargo and released in coordination with Rab/exocyst function. Dev. Cell 23, 769781. doi: 10.1016/j.devcel.2012.09.001 
Estravís, M., Rincón, S. A., Santos, B., and Pérez, P. (2011). Cdc42 regulates multiple membrane traffic events in fission yeast. Traffic 12, 1744-1758. doi: 10.1111/j.1600-0854.2011.01275.x d

Feig, L. A., Urano, T., and Cantor, S. (1996). Evidence for a Ras/Ral signaling cascade. Trends Biochem. Sci. 21, 438-441. doi: 10.1016/S0968-0004(96)10058-X

Fendrych, M., Synek, L., Pecenková, T., Drdová, E. J., Sekeres, J., de Rycke, R., et al. (2013). Visualization of the exocyst complex dynamics at the plasma membrane of Arabidopsis thaliana. Mol. Biol. Cell 24, 510-520. doi: 10.1091/mbc.E12-06-0492

Fendrych, M., Synek, L., Pecenkova, T., Toupalova, H., Cole, R., Drdova, E., et al. (2010). The Arabidopsis exocyst complex is involved in cytokinesis and cell plate maturation. Plant Cell 22:3053-3065. doi: 10.1105/tpc.110.074351

Finger, F. P., Hughes, T. E., and Novick, P. (1998). Sec3p is a spatial landmark for polarized secretion in budding yeast. Cell 92, 559-571. doi: 10.1016/S00928674(00)80948-4

Fukai, S., Matern, H. T., Jagath, J. R., Scheller, R. H., and Brunger, A. T. (2003). Structural basis of the interaction between RalA and Sec5, a subunit of the sec6/8 complex. EMBO J. 22, 3267-3278. doi: 10.1093/emboj/cdg329

Fu, Y., Wu, G., and Yang, Z. (2001). Rop GTPase-dependent dynamics of tiplocalized F-actin controls tip growth in pollen tubes. J. Cell Biol. 152, 1019-1032. doi: $10.1083 /$ jcb.152.5.1019

Guo, W., Roth, D., Walch-Solimena, C., and Novick, P. (1999). The exocyst is an effector for Sec4p, targeting secretory vesicles to sites of exocytosis. EMBO J. 4, 71-80.

Hála, M., Cole, R., Synek, L., Drdová, E., Pec̀enková, T., Nordheim, A., et al. (2008). An exocyst complex functions in plant cell growth in Arabidopsis and tobacco. Plant Cell 20, 1330-1345. doi: 10.1105/tpc.108.059105

Hammer, J. A., and Sellers, J. R. (2012). Walking to work: roles for class V myosins as cargo transporters. Nat. Rev. Mol. Cell. Biol. 13, 13-26. doi: 10.1038/nrm3248

Hazak, O., Bloch, D., Poraty, L., Sternberg, H., Zhang, J., Friml, J., etal. (2010). A RHO scaffold integrates the secretory system with feedback mechanisms in regulation of auxin distribution. PLoS Biol. 8:e1000282. doi:10.1371/journal.pbio.1000282

Hazelett, C. C., and Yeaman, C. (2012). Sec5 and Exo84 mediate distinct aspects of RalA-dependent cell polarization. PLoS ONE 7:e39602. doi: 10.1371/journal.pone.0039602

He, B., Xi, F., Zhang, X., Zhang, J., and Guo, W. (2007). Exo70 interacts with phospholipids and mediates the targeting of the exocyst to the plasma membrane. EMBO J. 26, 4053-4065. doi: 10.1038/sj.emboj.7601834

Heider, M. R., and Munson, M. (2012). Exorcising the exocyst complex. Traffic 13, 898-907. doi: 10.1111/j.1600-0854.2012.01353.x

Holubcová, Z., Howard, G., and Schuh, M. (2013). Vesicles modulate an actin network for asymmetric spindle positioning. Nat. Cell Biol. 15, 937-947. doi: $10.1038 /$ ncb 2802

Hsu, S. C., Ting, A. E., Hazuka, C. D., Davanger, S., Kenny, J. W., Kee, Y., et al. (1996). The mammalian brain rsec6/8 complex. Neuron 6, 209-219.

Jin, R., Junutula J. R., Matern H. T., Ervin K. E., Scheller R. H., and Brunger A. T. (2005). Exo84 and Sec5 are competitive regulatory Sec6/8 effectors to the RalA GTPase. EMBO J. 24, 2064-2074. doi: 10.1038/sj.emboj.7600699

Jin, Y., Sultana, A., Gandhi, P., Franklin, E., Hamamoto, S., Khan, A. R., etal. (2011). Myosin V transports secretory vesicles via a Rab GTPase cascade and interaction with the exocyst complex. Dev. Cell 21, 1156-1170. doi: 10.1016/j.devcel.2011.10.009

Jourdain, I., Dooley, H. C., and Toda, T. (2012). Fission yeast sec3 bridges the exocyst complex to the actin cytoskeleton. Traffic 13, 1481-1495. doi: 10.1111/j.16000854.2012.01408.x

Kono, K., Saeki, Y., Yoshida, S., Tanaka, K., and Pellman, D. (2012). Proteasomal degradation resolves competition between cell polarization and cellular wound healing. Cell 150, 151-164. doi: 10.1016/j.cell.2012.05.030

Krendel, M., Zenke, F. T., and Bokoch, G. M. (2002). Nucleotide exchange factor GEF-H1 mediates cross-talk between microtubules and the actin cytoskeleton. Nat. Cell Biol. 4, 294-301. doi: 10.1038/ncb773

Kulich, I., Cole, R., Drdová, E., Cvrčková, F., Soukup, A., Fowler, J., et al. (2010). Arabidopsis exocyst subunits SEC8 and EXO70A1 and exocyst interactor ROH1 are involved in the localized deposition of seed coat pectin. New Phytol. 188, 615-625. doi: 10.1111/j.1469-8137.2010.03372.x

Lavy, M., Bloch, D., Hazak, O., Gutman, I., Poraty, L., Sorek, N., et al. (2007). A Novel ROP/RAC effector links cell polarity, root-meristem maintenance, and vesicle trafficking. Curr. Biol. 17, 947-952. doi: 10.1016/j.cub.2007.04.038
Li, S., Gu, Y., Yan, A., Lord, E., and Yang, Z. B. (2008). RIP1 (ROP Interactive Partner 1)/ICR1 marks pollen germination sites and may act in the ROP1 pathway in the control of polarized pollen growth. Mol. Plant 1, 1021-1035. doi: $10.1093 / \mathrm{mp} / \mathrm{ssn} 051$

Liu, J., and Guo, W. (2012). The exocyst complex in exocytosis and cell migration. Protoplasma 249, 587-597. doi: 10.1007/s00709-011-0330-1

Liu, J., Zhao, Y., Sun, Y., He, B., Yang, C., Svitkina, T., et al. (2012). Exo70 stimulates the Arp2/3 complex for lamellipodia formation and directional cell migration. Curr. Biol. 22, 1510-1515. doi: 10.1016/j.cub.2012.05.055

Lovy-Wheeler, A., Wilsen, K. L., Baskin, T. I., and Hepler, P. K. (2005). Enhanced fixation reveals the apical cortical fringe of actin filaments as a consistent feature of the pollen tube. Planta 221, 95-104. doi: 10.1007/s00425-004-1423-2

Martiniere, A., Gayral, P., Hawes, C., and Runions, J. (2011). Building bridges: formin 1 of Arabidopsis forms a connection between the cell wall and the actin cytoskeleton. Plant J. 66, 354-365. doi: 10.1111/j.1365-313X.2011.04497.x

Martinière, A., Lavagi, I., Nageswaran, G., Rolfe, D. J., Maneta-Peyret, L., Luu, D. T., etal. (2012). Cell wall constrains lateral diffusion of plant plasmamembrane proteins. Proc. Natl. Acad. Sci. U.S.A. 109, 12805-12810. doi: 10.1073/pnas.1202040109

McFarlane, H. E., Young, R. E., Wasteneys, G. O., and Samuels, A. L. (2008). Cortical microtubules mark the mucilage secretion domain of the plasma membrane in Arabidopsis seed coat cells. Planta 227, 1363-1375. doi: 10.1007/s00425-0080708-2

Mohammadi, S., and Isberg, R. R. (2013). Cdc42 interacts with the exocyst complex to promote phagocytosis. J. Cell Biol. 200, 81-93. doi: 10.1083/jcb.201204090

Morgera, F., Sallah, M. R., Dubuke, M. L., Gandhi, P., Brewer, D. N., Carr, C. M., etal. (2012). Regulation of exocytosis by the exocyst subunit Sec6 and the SM protein Sec1. Mol. Biol. Cell 23, 337-346. doi: 10.1091/mbc.E11-080670

Moskalenko, S., Tong, C., Rosse, C., Mirey, G., Formstecher, E., Daviet, L., et al. (2003). Ral GTPases regulate exocyst assembly through dual subunit interactions. J. Biol. Chem. 278, 51743-51748. doi: 10.1074/jbc.M308702200

Mucha, E., Hoefle, C., Hückelhoven, R., and Berken, A. (2010). RIP3 and AtKinesin$13 \mathrm{~A}$ - a novel interaction linking Rho proteins of plants to microtubules. Eur. J. Cell. Biol. 89, 906-916. doi: 10.1016/j.ejcb.2010.08.003

Mucha, E., Fricke, I., Schaefer, A., Wittinghofer, A., and Berken, A. (2011). Rho proteins of plants-functional cycle and regulation of cytoskeletal dynamics. Eur. J. Cell Biol. 90, 934-943. doi: 10.1016/j.ejcb.2010.11.009

Mukerji, J., Olivieri, K. C., Misra, V., Agopian, K. A., and Gabuzda, D. (2012). Proteomic analysis of HIV-1 Nef cellular binding partners reveals a role for exocyst complex proteins in mediating enhancement of intercellular nanotube formation. Retrovirology 9:33. doi: 10.1186/1742-4690-9-33

Nakano, K., Toya, M., Yoneda, A., Asami, Y., Yamashita, A., Kamasawa, N., et al. (2011). Pob1 ensures cylindrical cell shape by coupling two distinct Rho signaling events during secretory vesicle targeting. Traffic 12, 726-739. doi: 10.1111/j.16000854.2011.01190.x

Nalbant, P., Chang, Y. C., Birkenfeld, J., Chang, Z. F., and Bokoch, G. M. (2009). Guanine nucleotide exchange factor-H1 regulates cell migration via localized activation of RhoA at the leading edge. Mol. Biol. Cell 20, 4070-4082. doi: 10.1091/mbc.E09-01-0041

Nichols, C. D., and Casanova, J. E. (2010). Salmonella-directed recruitment of new membrane to invasion foci via the host exocyst complex. Curr. Biol. 20, 1316-1320. doi: 10.1016/j.cub.2010.05.065

Novick, P., Field, C., and Schekman, R. (1980). Identification of 23 complementation groups required for post-translational events in the yeast secretory pathway. Cell 21, 205-215. doi: 10.1016/0092-8674(80)90128-2

Oda, Y., and Fukuda, H. (2012). Secondary cell wall patterning during xylem differentiation. Curr. Opin. Plant Biol. 15, 38-44. doi: 10.1016/j.pbi.2011.10.005

Ohno, H., Hase, K., and Kimura, S. (2010). M-Sec: emerging secrets of tunneling nanotube formation. Commun. Integr. Biol. 3, 231-233. doi: 10.4161/cib.3.3.11242

Pathak, R., Delorme-Walker, V. D., Howell, M. C., Anselmo, A. N., White, M. A., Bokoch, G. M., et al. (2012). The microtubule-associated Rho activating factor GEF-H1 interacts with exocyst complex to regulate vesicle traffic. Dev. Cell 23, 397-411. doi: 10.1016/j.devcel.2012.06.014

Pecenkova, T., Hala, M., Kulich, I., Kocourkova, D., Drdova, E., Fendrych, M., et al. (2011). The role for the exocyst complex subunits Exo70B2 and Exo70H1 in the plant-pathogen interaction. J. Exp. Bot. 62, 2107-2116. doi: 10.1093/jxb/erq402 
Rivera-Molina, F., and Toomre, D. (2013). Live-cell imaging of exocyst links its spatiotemporal dynamics to various stages of vesicle fusion. J. Cell Biol. 201, 673-680. doi: 10.1083/jcb.201212103

Sakurai-Yageta, M., Recchi, C., Le Dez, G., Sibarita, J. B., Daviet, L., Camonis, J., et al. (2008). The interaction of IQGAP1 with the exocyst complex is required for tumor cell invasion downstream of Cdc42 and RhoA. J. Cell Biol. 181, 985-998. doi: $10.1083 /$ jcb. 200709076

Schiller, C., Diakopoulos, K. N., Rohwedder, I., Kremmer, E., von Toerne, C., Ueffing, M., et al. (2013). LST1 promotes the assembly of a molecular machinery responsible for tunneling nanotube formation. J. Cell Sci. 126, 767-777. doi: $10.1242 /$ jcs. 114033

Shen, D., Yuan, H., Hutagalung, A., Verma, A., Kümmel, D., Wu, X., et al. (2013). The synaptobrevin homologue Snc2p recruits the exocyst to secretory vesicles by binding to Sec6p. J. Cell Biol. 202, 509-526. doi: 10.1083/jcb.201211148

Sivaram, M. V., Saporita, J. A., Furgason, M. L., Boettcher, A. J., and Munson, M. (2005). Dimerization of the exocyst protein Sec6p and its interaction with the t-SNARE Sec9p. Biochemistry 44, 6302-6311. doi: 10.1021/bi048008z

Snaith, H. A., Thompson, J., Yates, J. R., and Sawin, K. E. (2011). Characterization of Mug33 reveals complementary roles for actin cable-dependent transport and exocyst regulators in fission yeast exocytosis. J. Cell Sci. 124, 2187-2199. doi: 10.1242/jcs.084038

Songer, J. A., and Munson, M. (2009). Sec6p anchors the assembled exocyst complex at sites of secretion. Mol. Biol. Cell 20, 973-982. doi: 10.1091/mbc.E08-09-0968

Staehelin, L. A., and Moore, I. (1995). The plant golgi apparatus: structure, functional organization and trafficking mechanisms. Annu. Rev. Plant Physiol. Plant Mol. Biol. 46, 261-288. doi: 10.1146/annurev.pp.46.060195.001401

Sugihara, K., Asano, S., Tanaka, K., Iwamatsu, A., Okawa, K., and Ohta, Y. (2002). The exocyst complex binds the small GTPase RalA to mediate filopodia formation. Nat. Cell Biol. 1, 73-78. doi: 10.1038/ncb720

Sutter, J. U., Campanoni, P., Tyrrell, M., and Blatt, M. R. (2006). Selective mobility and sensitivity to SNAREs is exhibited by the Arabidopsis KAT1 K+ channel at the plasma membrane. Plant Cell 18, 935-954. doi: 10.1105/tpc.105.038950

Swiech, L., Blazejczyk, M., Urbanska, M., Pietruszka, P., Dortland, B. R., Malik, A. R., et al. (2011). CLIP-170 and IQGAP1 cooperatively regulate dendrite morphology. J. Neurosci. 31, 4555-4568. doi: 10.1523/JNEUROSCI.6582-10.2011

Synek, L., Schlager, N., Eliáš, M., Quentin, M., Hauser, M. T., and Žárský, V. (2006). AtEXO70A1, a member of a family of putative exocyst subunits specifically expanded in land plants, is important for polar growth and plant development. Plant J. 48, 54-72. doi: 10.1111/j.1365-313X.2006.02854.x

TerBush, D. R., Maurice, T., Roth, D., and Novick, P. (1996). The Exocyst is a multiprotein complex required for exocytosis in Saccharomyces cerevisiae. EMBO J. 15, 6483-6494.

Valentijn, K. M., Gumkowski, F. D., and Jamieson, J. D. (1999). The subapical actin cytoskeleton regulates secretion and membrane retrieval in pancreatic acinar cells. J. Cell Sci. 112, 81-96.

Vaškovičová, K., Žárský, V., Rösel, D., Nikolič, M., Buccione, R., Cvrčková, F., et al. (2013). Invasive cells in animals and plants: searching for LECA machineries in later eukaryotic life. Biol. Direct 8:8. doi: 10.1186/1745-6150-8-8

Vega, I. E., and Hsu, S. C. (2001). The exocyst complex associates with microtubules to mediate vesicle targeting and neurite outgrowth. J. Neurosci. 21, 3839-3848.
Wang, S., Liu, Y., Adamson, C. L., Valdez, G., Guo, W., and Hsu, S. C. (2004). The mammalian exocyst, a complex required for exocytosis, inhibits tubulin polymerization. J. Biol. Chem. 279, 35958-35966. doi: 10.1074/jbc.M313778200

White, C. D., Erdemir, H. H., and Sacks, D. B. (2012). IQGAP1 and its binding proteins control diverse biological functions. Cell. Signal 24, 826-834. doi: 10.1016/j.cellsig.2011.12.005

Wu, S., Mehta, S. Q., Pichaud, F., Bellen, H. J., and Quiocho, F. A. (2005). Sec15 interacts with Rab11 via a novel domain and affects Rab11 localization in vivo. Nat. Struct. Mol. Biol. 12, 879-885. doi: 10.1038/nsmb987

Wu, H., Rossi, G., and Brennwald, P. (2008). The ghost in the machine: small GTPases as spatial regulators of exocytosis. Trends Cell Biol. 18, 397-404. doi: 10.1016/j.tcb.2008.06.007

Wu, H., Turner, C., Gardner, J., Temple, B., and Brennwald, P. (2010). The Exo70 subunit of the exocyst is an effector for both $\mathrm{Cdc} 42$ and Rho 3 function in polarized exocytosis. Mol. Biol. Cell 21, 430-442. doi: 10.1091/mbc.E09-06-0501

Yalovsky, S., Bloch, D., Sorek, N., and Kost, B. (2008). Regulation of membrane trafficking, cytoskeleton dynamics and cell polarity by ROP/RAC GTPases. Plant Phys. 147, 1527-1543. doi: 10.1104/pp.108.122150

Zakharenko, S., and Popov, S. (1998). Dynamics of axonal microtubules regulate the topology of new membrane insertion into the growing neurites. J. Cell Biol. 143, 1077-1086.

Žárský, V., Cvrčková, F., Potocký, M., and Hála, M. (2009). Exocytosis and cell polarity in plants - exocyst and recycling domains. New Phytol. 183, 255-272. doi: 10.1111/j.1469-8137.2009.02880.x

Zhang, X., Orlando, K., He, B., Xi, F., Zhang, J., Zajac, A., et al. (2008). Membrane association and functional regulation of Sec3 by phospholipids and Cdc42. J. Cell Biol. 180, 145-158. doi: 10.1083/jcb.200704128

Zhao, Y., Liu, J., Yang, C., Capraro, B. R., Baumgart, T., Bradley, R. P., et al. (2013). Exo70 generates membrane curvature for morphogenesis and cell migration. Dev. Cell 26, 266-278. doi: 10.1083/jcb.200704128

Zuo, X., Zhang, J., Zhang, Y., Hsu, S. C., Zhou, D., and Guo, W. (2006). Exo70 interacts with the Arp $2 / 3$ complex and regulates cell migration. Nat. Cell Biol. 8 , 1383-1388.

Conflict of Interest Statement: The authors declare that the research was conducted in the absence of any commercial or financial relationships that could be construed as a potential conflict of interest.

Received: 31 October 2013; paper pending published: 18 November 2013; accepted: 12 December 2013; published online: 02 January 2014.

Citation: Synek L, Sekereš J and Žárský V (2014) The exocyst at the interface between cytoskeleton and membranes in eukaryotic cells. Front. Plant Sci. 4:543. doi: 10.3389/fpls.2013.00543

This article was submitted to Plant Traffic and Transport, a section of the journal Frontiers in Plant Science.

Copyright (c) 2014 Synek, Sekereš and Žárský. This is an open-access article distributed under the terms of the Creative Commons Attribution License (CC BY). The use, distribution or reproduction in other forums is permitted, provided the original author(s) or licensor are credited and that the original publication in this journal is cited, in accordance with accepted academic practice. No use, distribution or reproduction is permitted which does not comply with these terms. 